\title{
The energy policy outlets for community acceptance of ecological investment in China
}

DOI:

10.1016/j.enpol.2017.03.062

\section{Document Version}

Accepted author manuscript

Link to publication record in Manchester Research Explorer

\section{Citation for published version (APA):}

Wang, Z., \& Deng, X. (2017). The energy policy outlets for community acceptance of ecological investment in China. Energy Policy. https://doi.org/10.1016/j.enpol.2017.03.062

\section{Published in:}

Energy Policy

\section{Citing this paper}

Please note that where the full-text provided on Manchester Research Explorer is the Author Accepted Manuscript or Proof version this may differ from the final Published version. If citing, it is advised that you check and use the publisher's definitive version.

\section{General rights}

Copyright and moral rights for the publications made accessible in the Research Explorer are retained by the authors and/or other copyright owners and it is a condition of accessing publications that users recognise and abide by the legal requirements associated with these rights.

\section{Takedown policy}

If you believe that this document breaches copyright please refer to the University of Manchester's Takedown Procedures [http://man.ac.uk/04Y6Bo] or contact uml.scholarlycommunications@manchester.ac.uk providing relevant details, so we can investigate your claim.

\section{OPEN ACCESS}




\title{
The energy policy outlets for community acceptance of ecological investment in China
}

\author{
Zhan Wanga,b,c,d \& Xiangzheng Deng ${ }^{\mathrm{c}, \mathrm{d} *}$ \\ a School of Economics \& Management, Beijing Forestry University, Beijing 100083, \\ P.R. of China. E-Mail: wangz@igsnrr.ac.cn (Z.W.); \\ ${ }^{\mathrm{b}}$ School of Environment, Education \& Development, The University of Manchester, \\ M13 9PL, United Kingdom. \\ ${ }^{\mathrm{c}}$ Institute of Geographic Sciences and Natural Resources Research, Chinese Academy \\ of Sciences, Beijing 100101, P.R. of China. Email: dengxz@igsnrr.ac.cn (X.D.); \\ ${ }^{\mathrm{d}}$ Center for Chinese Agricultural Policy, Chinese Academy of Sciences, Beijing \\ 100101, P.R. of China. Email: dengxz.ccap@igsnrr.ac.cn (X.D.);
}

* Corresponding Authors to Prof. Dr. Xiangzheng Deng at E-mail: dengxz@igsnrr.ac.cn (X.D.); Tel.: +86-10-64888980; Fax: +86-10-64856533.

\begin{abstract}
Policy implication about satisfactions of energy use and housing are much sensitive to social discount rate changes, which can increase the dissatisfaction of residential happiness because of an increasing price mechanism when 'per capita' resource faces to decline. We thus estimate the private expected rates of return on ecological investment to improve urban and peri-urban environmental infrastructures are about to $7.54 \%$ and $18.37 \%$ respectively. The endogeneities of income and saving rise can increase the uncertain part of private discount rate up to a higher estimated subjective social discount rate about $14.46 \%$ for urban or $8.86 \%$ for peri-urban environmental infrastructures improvement. The estimated time preference rate can be raised from $1 \%$ to $1.72 \%$. The prediction of these estimated private discount rate can ease at least $20 \%$ of the dissatisfaction to energy use and $10 \%$ of the dissatisfaction to housing conditions. Therefore, we suggest opening the landscape rights to individual willingness-to-invest, and providing options to let people pay a part of their pensions for temporal permits to living in some well-served villages where are close to the places with advanced environmental amenities and being supported by central planning policy via the crowdfunding operation for improving environmental quality.
\end{abstract}

Keywords: Community; Ecological payments; Eco-urbanization; Energy policy; Landscape 


\section{Introduction}

Before this paper written, COP21/CMP11 at Paris 2015 proposed a much more flexible plan for multilateral cooperation of emission mitigation. It presents a bottom-up framework design reflecting the initiative 'acceptance' of emission mitigation in every participating country. This logic is clear that a bottom-up scheme has an initial level in a country. However, it is uncertain that sub-national regulations and individual choices for ecologically friendly behaviors.

The initiative 'acceptance' of emission mitigation at sub-national level highly likely contains more uncertainties. Unlike the legislations and regulations are always top-down implements, community acceptance of cleaner goods usually falls to a sticky situation when residents would get a more expensive bill of living expense. On the one hand, environmental conservation responsibility is regulated in a blurry way in laws and ordinances of some developing countries which are usually too broad to be implemented because mixed regulations of environmental governance at different ranks of administrative hierarchy are expressed in a manner of "what should be" rather than "what in fact". The planning laws that try to fix this gray gap between "should be" and "be in fact", but on the other hand, regional cooperation for environmental conservation usually is very hard to be financed. Especially, market solutions for five key industries: manufacture, transportation, agriculture, tourism, and renewable energy are still seeking policy outlets of cleaner production for green growth. Thereby, environmental justice is stressed as the kernel concept of natural law by current academic community.

Intergeneration and intrageneration equality issues present environmental justice which is usually argued by social or private discount rate. Weitzman (1994) proposed an "environmental" discount rate to show that the social discount rate "ought to be" 
lower than the private discount rate because an increasing environmental payment would occur in the future. However, some empirical estimations disobey this theoretical results. Social discount rates (8-15\%) in developing countries in general are higher than that in developed countries (3-7\%), while private discount rates by survey estimates are much lower (1-3\%) in all countries (Zhuang et al., 2007; Harrison, 2010). Environmental economists try to figure out this gap by valuing natural asset and seeking policy outlets of renewable energy, and aim to provide investment choices for heterogeneous demands at lower level of social structure, such as at community level, because heterogeneous groups may impede the energy policy being implemented uniformly (Bauwens, 2016). Researchers currently prefer to estimate a willingness-topay (WTP) for initiative choice to renewable energy in Asia countries (Lee \& Heo, 2016). Moreover, such like China engages an ambitious agenda of urbanization which will bring a huge government investment on infrastructures, and force structural reformation in industrial structure, land use structure, resources and energy use (Forman $\& \mathrm{Wu}, 2016)$. Facing these gaps, we do not only need time, but tremendous investments to support economic growth, thus where are the energy policy outlets for community acceptance to invest and consume low-carbon choices?

\subsection{China's legislations on environmental conservation and energy use}

The People's Republic of China Environmental Impact Assessment Law was firstly promulgated on October $29^{\text {th }}$ in 2002 right after the sixth Environment Action Programme of the European Community was implemented ${ }^{1}$, which clarified in the first

\footnotetext{
${ }^{1}$ Recall a milestone on the 1972 Paris summit, European Economic Community (EEC) at the first time proposed the environmental policy framework. This historical mark stated that economic growth per se is not the ultimate target of economic development, instead, it should improve the living standard and healthy life quality, narrow down the income disparity in priority, and pay attention to intangible value of indigenous knowledge and environmental conservation for better serving humanity. During the thirty
} 
of 38 articles that "in order to implement the strategy of sustainable development, to prevent the adverse effects on the environment after the planning and construction project implementation, and to promote the economic, social and environmental coordinative development, this law is enacted." Contemporaneously, rural-urban transforming construction has been vigorously developed, which is so called the plan of "village-dismission and town-combination". During 1985-2007, there were 68062 revoked townships (Xiāng) and 411 revoked counties, but established 11293 town (Zhèn) governments. This national transformation induced many planning issues and environmental degradation. China's central government took actions to promulgate The People's Republic of China Renewable Energy Law on February $28^{\text {th }}$ in 2005 , and The People's Republic of China Energy Conservation Law and The People's Republic of China Urban and Rural Planning Law on October $28^{\text {th }}$ in 2007. These legislations regulate land management, natural resource exploration, environmental conservation, and energy use; and encourage scientific innovation and private investment to advanced technology in these aspects. While, urbanization successively brings about intense energy use and regional environmental degradation. National Bureau of Statistics of China reported that per capita energy consumption of daily living in mainland China was about $346.1 \mathrm{~kg}$ of standard coal in 2014, while this number in Beijing is about

years of 1972-2002, EEC successively set up six Environmental Action Programmes which pushed the establishment of European Union (EU) formed in 2002. The first programme stressed technology innovation for responding to natural hazards. The second programme focused on regulations to the standards of air, water, soil, and materials processing. The third programme further stressed the Best Available Technique (BAT) for coastwise protection, noise reduction, and transboundary pollution mitigation. The fourth programme encouraged four special sectors (agriculture, industry, transportation, and energy) transformed to more ecologically friendly actions, and put forward to the standardized planning instrument (physical planning). The fifth programme postulated a principle of sustainable development is a compatible target of economic and ecological objectives, and directed to environmental quality standards rather than emission standards. During 2002-2012, the six programme advocated stricter legislations and regulations of environmental quality for benefit to stockholders, which pointed out seven strategic aspects including air pollution, marine environment, renewable energy, waste recycling, sustainable pesticide, soil catena, and urban environment, and further push land use planning and individual choices being involved into behavioral changes. 
$705.3 \mathrm{~kg}$ of standard coal in 2014. The People's Republic of China Environmental Protection Law was implemented on January $1^{\text {st }}$ in 2015 which further claims 70 articles to push environmental and economic coordinative development for a new type of urbanization. The $35^{\text {th }}$ article firstly mentions rural-urban construction should rely on geological characters to protect vegetation, water area, and natural landscape, and enhance construction and management of urban parks, greening land, and historical scenic spots. The laws also encourage individuals, firms, and other organizations invest on renewable energy, recycling products, waste reduction processing, and transboundary pollution management for environmental conservation, and The People's Republic of China Energy Law still being discussed in draft until 2016.

There are two main challenges of renewable energy use in China. The first is high cost of transformative technology, and the second is community initiative acceptance of expansive energy bill in cities. Moreover, Moriarty \& Honnery (2016) examined global renewable energy use during 2004-2014 and found renewable energy development may also induce environmental degradation because of lower investment on conservation technology. Some private investments also confront some discomfiture of lower profit return on renewable energy technology. Advanced innovative technology of renewable energy can enter market only relying on government subsidy and administrative regulation in China (Cao, Kleit \& Liu, 2016). On the positive side, fiscal policy stimulates high-tech firm establishment; on the other side, some inefficient innovation lead to financial losses (Huang et al., 2012). Furthermore, environmental pollution control payment is getting large. While, environmental pollution risk has been also getting higher in the past decade since The People's Republic of China Environmental Impact Assessment Law implemented in 2003 (Wang et al., 2016). Thus, 
how long and how much can government afford this increasing payment? Especially, when the declining economic growth are expected views, quantitative easing may not work out this trap. Investment transformation implies a brighter future, but ultimately consumer is the judger.

Carbon sequestration market may not satisfy current China's emission demands due to uncertainties (Ang, Su \& Wang, 2016; Chen et al., 2013; Zhou \& Wang, 2016). Zhang et al. (2017) found that government policies for increasing energy efficiency in fact are always lagged behand carbon emission reduction in China. It infers that initiative mitigation of Greenhouse Gas (GHG) emission at provincial level is more efficient than that at national level policy via a promising carbon trade mechanism (Zhou, et al., 2014; Zhang, 2015). However, it is questionable that whether a promising financial system can efficiently allocate the uncertainties of climate changes to lower the risk of carbon market. Zhang, Jiao \& Chen (2017) introduced the demand-side energy management framework in China which directs to a firm level implementation for absorbing private investment to advanced innovations. However, those policies are highly likely neglected by private firms due to lower profit return rate. Some phenomena have occurred. For instance, if there is a high-teach company received an angel investment for cleaner production technology, instead of being used to manufacture, it can sell their improved patents to another company after their price rises for earning profits easily. These economic statistics can be shown as innovation investment return, and the followers would get some favorable taxation rate for running a new high-tech company. This increased gross domestic product will be recorded into the throughputs in service sector of social production, or recorded into the industrial sector if some manufactures own shares of this kind of high-tech companies. It implies 
that the financial system takes the risk of this 'inefficient innovations', and which becomes more uncertainly to reflect the real manufacturing performance in cleaner production. Thus, will a carbon market be efficient to allocate the risk of firm behaviors for more profits or for further cleaner production? Can individual choice play a role in an ecological investment market? Will it be more efficient for improving their own livable environment in China?

\subsection{Landscape rights for individual choices}

The urbanizing process in China is quite different from other countries'. Rich people in developed countries prefer to live in rural places where have better environmental amenities, while poor people in China are left at rural area. Vast natural forest and ecological conservation regions are financially subsidized by central planning system. Such like forestry and marine sectors in many countries, natural capitals are poorly operated with much low profits, and investors have strong preferences to ecological value being marketized (Leete, $\mathrm{Xu} \&$ Wheeler, 2013). Many researchers make great efforts on valuing ecosystem service, however, such as carbon sequestration market cannot directly benefit to individuals. This situation is partially caused by unsharp rights of land and resource property rights with undefined spatial diversity in a community. Different countries hold diverse characters of population and land resources. For instance, in USA, owning a piece of land means to own all resources under and above the surface of land, and where urbanization is prone to be an urban sprawl process, but this scheme is not appropriate to a populous country with less livable land resources. Such like China, people do not be allowed to own a piece of land. Urbanization makes people crowd in the cities and left empty houses in rural hometowns. This leads to more intense resource and energy use at urbanizing area, and left poorly developed ecological 
conservation regions in rural places. Experiences from some European countries, some ventures can only own the land cover and above a certain height from the land cover by planning laws regulated. These clarifications of landscape rights let spatial diversities can be defined for benefiting to property management. Whereas, individual investment on ecological projects in China are impossible mainly because there is no a mechanism for separating space above the land and running it as a usual business.

How to price landscapes? Arguments are research methods of traditional costbenefit analysis based on local willingness-to-pay for public amenities of landscapes. O'neill \& Walsh (2000) pointed out local willingness-to-pay cannot sufficiently cover the cost of national parks conservation because diverse preferences of landscape reflect conflicts that cannot be identified by clear property rights in UK. Penker (2009) further demonstrated that local willingness-to-pays cause the gap of cost-benefit that cannot be compensated because of relatively less people who live near to national parks in Austrian rural area. Janssen-Jansen (2008) introduced "a transferable development rights initiative" in Dutch rural-urban transformation which let government finance the housing plans on former livestock farms. It infers that land property rights can be temporally transformed to landscape development right and housing owning right separately. Hess (2010) researched some phenomena of nail-houses which fragment landscapes, and further discussed land rights issues in China. Housing properties of householders in China currently are temporally contracted with central government. This formative contract separates land property right and housing owning right, but so far there is no clearly separated priced landscape rights.

Public goods can be managed separately by people who are interested in monitoring their share of benefits from public goods, and earning profits from premium 
of environmental quality. China has a large population. With household income increases, people are getting attentions to environmental protection. Their strong demands currently are still hard to be priced. Carbon sequestration market provides opportunities to firms, but neglects individuals' willingness-to-pay for improving environmental quality. Crowdfunding of environmental conservation may be an outlet for investing renewable energy projects, aging public facilities, and other policypermitted preferences. This is a concept that the collaborative investment to an integrated management scheme makes profits for public common amenities. It means to share blurry rights of public properties but manage them in an individual's manner for earning profits together under an integrated scientific monitoring framework.

In the rest of paper, we will firstly introduce the case study design and describe survey data in section 2; then illustrate the empirical models of individual's willingnessto-pay for ecological investment in section 3; present results in section 4; discuss the relevant policy outlets in section 5; and give our conclusion in the last section 6 .

\section{Case study design and survey data}

Beijing is the capital of P.R. of China. Until 2015, population was 21.705 million distributed in 16 districts. In previous research, we find that one percentage of population increases can lead to $1.96-2 \%$ of pooled growth rate of land use efficiency of built-up land changes during 2005-2008 (Wang et al., 2017). It has violated the regional target of land use planning if the income effects do not be taken into consideration of estimation in Beijing-Tianjin-Hebei region of China. Strong ecological intercorrelation can increase over ten present of spillover effects exceeding backwardwave effect in this region (Wang et al., 2017). It implies that the increases of regional 
transportation demand with population increases are not the root of urban problems and environmental degradations. Over 88 percent of respondents agree with that road quality has a relationship with environmental quality. More roads in a well-designed transportation system do not have significantly negative impacts on environmental quality degradation (Deng et al., 2011; Wang \& Deng, 2017). Relationships between economic income distribution and spatial allocations of environmental amenities are critical points to urban growth and environmental quality improvement. Such as energy policies and environmental planning legislations are display vectors and enforcement bases to guarantee a rise of living standard. In this case, community acceptance and satisfaction of these stipulates represent the most of public options. Thus, we surveyed residents' willingness-to-pay for improving urban and peri-urban environmental infrastructures to environmental quality improvement (EI-Q) in Beijing, and asked their expected rate of return on ecological investment, then estimated impact factors to this private discount rate changes.

This basic idea is to invest their environmental funding share just like to manage their pension but do not be limited by residential locations; instead, they can own multiple permits of residential identification for temporally living in some government financed (or partial financed) nursing houses where are close to some ecological conservation parks. We asked a dichotomous question that "Do you think environmental protection benefit to future generation?" There were near to 95 percent of respondents who answered "Yes". Sequentially, we asked their expected rates of return on investment to keep environmental quality for future generation when they consider their investments as savings without time preference in Figure 1. 
Figure 1 Distribution of respondent expected rate of return on ecological investment $(\%)$ to keep environmental quality for future generation without time preference in Beijing of China, 2016.

There are about 150-230 million CNY per month in a total amount of willingnessto-pay for improving environmental infrastructures ${ }^{2}$ to urban environmental quality improvement, and 60-120 million CNY per month for improving environmental infrastructures to peri-urban environmental quality improvement. Over 47 percent of respondents expected rate of return on ecological investment is over one percent, and over 38 percent of respondents expected this private discount rate over two percent to keep environmental quality for future generation without time preference in 2016 summer survey at Beijing of China. We list impact factors on this expected private discount rate estimation including gender, age, social status (represented by education, job, and car owner), economic status (represented by per capita annual household income, and saving rate of per capita annual household income), current attitudes on consumption (represented by satisfaction of transportation, electronic appliances use, energy use, food consumption, housing and living condition, and satisfaction of urban and peri-urban amenities), and awareness of ecological infrastructures in the Table 1 (data sources by Wang \& Deng et al. 2016).

Table 1 Statistics description of impact factors on survey respondent expected rate of return on ecological investment $(\%)$ to keep environmental quality for future generation without time preference in Beijing of China, 2016.

\footnotetext{
${ }^{2}$ Gray infrastructures: land use for building construction and public service; and Green infrastructures: so-called "ecological infrastructure", which is including dry/paddy (cultivated) land, woodland, grassland, water/wetland, and unused land in urban and peri-urban area defined by Li et al., 2016.
} 


\section{Empirical model}

Wang et al. (2017) have examined that environmental income can be a part of premium from the improvement of environmental quality which contributes to increase saving rate for driving consumption changes dynamically. This ecological investment will drive earning extra environmental income. In this case, to balance a potential relative increase of consumption, a lump-sum environmental taxation on every unit of consumption can redistribute the consumption rise if the renewable resource can be transformed to increase capital accumulation in a high efficiency. Thereby, we designed an empirical study framework to survey willingness-to-pay for ecological investment in Beijing. This design follows several assumptions. (1) Land property rights have been clarified much clear in highly urbanized region than in peri-urban regions. (2) There are still some gaps between different ecological investments to urban and peri-urban area which lead to inequality of environmental quality at community level and unbalanced economic growth in a region. (3) Residential willingness-to-pays are influenced by their personal identities, social status, economic status, current attitudes of consumption, and awareness of ecological infrastructures. (4) If landscape rights can be priced by this private willingness-to-pay for ecological investment, environmental income in relative utilities (between consumption and ecological investment) can be estimated by expected discount rate of environmental quality and other impact factors such as personal identities, economic status, current attitudes of consumption, and awareness of ecological infrastructures to improve environmental quality.

Empirical model I: to estimate the uncertain gap between private and social discount rate of ecological investment. The social discount rate is prone to be a constant 
which can be shifted because of social norms or uncertainties of future (Baumol, 1968). The higher probability is that current generation concerns about future environmental issues and climate changes for their generations, the higher satisfaction of current income and consumption level will be reached; otherwise individual utility maximization can drag over-consumption of future benefits of natural environment. Thereby, Weitzman (1994) proved that an environmental discount rate exists because there is a gap between private and social discount rate. Dasgupta (2008) further proposed that this gap of environmental discount rate can be altered by the marginal utility changes when consumption share rise, so that the social discount rate is prone to be a consistent number. If future generation gets richer, the elasticity of marginal utility to the previous consumption level will get larger. It may cause less expected savings and increasing current marginal utility of consumption, or cause more expected precautionary savings for future uncertainties. This depends on individuals' choices of environmental friendly behaviors. Suppose individuals' willingness-to-pay can present their choices of environmental friendly behaviors, we can estimate their choices with respect to expected private discount rate, current marginal utility of consumption, and current precautionary saving rate (actual saving share of income) for future uncertainties. Thus, we have the equation (1) to present willingness-to-pay for ecological investment $[W T P]$ share $[y]$ of per capita household income [inc] which is the trade-off between the utility of saving $\left[U_{s}\right]$ and the utility of consuming $\left[U_{c}\right]$ every unit of environmental infrastructures as follows.

$$
y_{i}=\frac{W T P_{i}}{\text { inc }_{i}}=\frac{U_{s}}{U_{c}}\left\{\begin{array}{cc}
U_{s}>0 ; U_{c}>0 & \text { if } W T P_{i}>0 \\
\lim _{U_{c} \rightarrow \infty} U_{s}=0 & \text { if } W T P_{i}=0
\end{array} \quad i=1,2, \ldots, o b s\right.
$$


where ecological investment denotes the attitude in between environmental conservation and resource consumption. If we suppose time preference is zero in advance, it implies all respondents are somehow unsatisfied about current environment. The classical formula of discount rate (Ramsey, 1928) then can be rewritten by the following equation (2).

$$
y_{i}=\frac{r_{i}}{g_{i}}, i=1,2, \ldots, o b s
$$

where $r_{i}$ is the subjective social discount rate and $g_{i}$ is the rate of individual consumption rise. Thereby, there are relationships of willingness-to-pay with the social discount rate and individuals' consumption changes in this reduced empirical model I in equation (3).

$$
\ln W T P_{i}=\ln r_{i}+\left[\beta \ln i n c_{i}-\gamma \ln g_{i}\right]+\mu_{i}+\varepsilon_{i}, \quad i=1,2, \ldots, o b s
$$

where the subjective social discount rate $r$ is supposed as a constant, and $\mu$ is the uncertain private discount rate $[p d r]$ which is highly relevant to respondents identity such as gender [gender], age [age], social status (represented by education [edu], job [job], car owner [car]), economic status (represented by saving rate [saving] of annual household income per capita [inc]); and the rate of consumption rise $g_{i}$ depends upon the current attitude of consumption (represented by respondent satisfaction of transportation [trans], electronic appliances use [ele], energy use [energy], food consumption [food], housing and living condition [hous], and satisfaction of economic condition [econ], and satisfaction of urban and peri-urban amenities [sua and spa], and respondent awareness of ecological infrastructures (EI) [awu and $a w p]$ ). $\varepsilon$ is the disturbance term. Thus, the empirical model I can be extended with relationships of the private discount rate to these control variables. 
Empirical model II: to identify endogeneities of individual impact factors to the uncertain part of private discount rate changes. For instance, income rise may narrow down the gap between social discount rate and private discount rate due to intrageneration time preference rate rise, or it may enlarge the gap because relative higher consumption rate for seeking premium of environmental change risks. In this case, there may have endogenous income redistributed effects on private discount rate changes. Based on equation (4), we can reach this empirical model II as follows.

$$
\mu=\mu_{i}(p d r, \text { inc, gender, age }, e d u, \text { job, car, saving, current attitude })
$$

The estimated social discount rate $\tilde{\hat{r}}$ of empirical model II can be reached by the estimated $\hat{r}$ plus the estimated uncertain part of private discount rate $\hat{\mu}$ from the empirical model I as shows by equation (5). Moreover, the subtracted difference between $\hat{\mu}$ and the estimated $\tilde{\beta}$ times the total rate of consumption rise $\tilde{\gamma}$ of empirical model II approximately is the estimated time preference rate $\sigma$ in equation (6), which can also test the deviation from our assumption in empirical model I that suppose the time preference rate is much close to zero.

$$
\begin{gathered}
\tilde{\hat{r}}=\hat{r}+\hat{\mu} \\
\sigma=\hat{\mu}-\tilde{\beta} \tilde{\gamma}
\end{gathered}
$$

Empirical model III: to estimate an expected rate of return on ecological investment after further estimated social discount rate of ecological investment. Recall the trade-off $[y]$ between the utility of saving $\left[U_{s}\right]$ and the utility of consuming $\left[U_{c}\right]$ every unit of environmental infrastructures, which can be present by willingness-to-pay for ecological investment [WTP] share of per capita annual household income [inc] in equation (1). Under our first assumption that land property rights have been clarified 
much clear in highly urbanized region than in peri-urban regions. There is a gap between urban $[u]$ and peri-urban $[p]$ ecological investment share changes in per capita household income. Thus, we separate equation (1) in two parts as follows in equation (7-8).

$$
\begin{gathered}
y_{u i}=\frac{W T P_{u i}}{i n c_{i}}=\frac{U_{u s}}{U_{u c}}\left\{\begin{array}{cc}
U_{u s}>0 ; U_{u c}>0 & \text { if } W T P_{u i}>0 \\
\lim _{U_{u c} \rightarrow \infty} U_{u s}=0 & \text { if } W T P_{u i}=0
\end{array} \quad i=1,2, \ldots, o b s\right. \\
y_{p i}=\frac{W T P_{p i}}{i n c_{i}}=\frac{U_{p s}}{U_{p c}}\left\{\begin{array}{cc}
U_{p s}>0 ; U_{p c}>0 & \text { if } W T P_{p i}>0 \\
\lim _{U_{p c} \rightarrow \infty} U_{p s}=0 & \text { if } W T P_{p i}=0
\end{array} \quad i=1,2, \ldots, o b s\right.
\end{gathered}
$$

To seek policy outlets of absorbing ecological investment, we will estimate marginal effects of respondent expected private discount rate that initiate the ecological investment share of per capita annual household income $[y]$ for improving urban and peri-urban environmental infrastructures under their current attitude of consumption and awareness of ecological infrastructures. Recall equation (2), and suppose $\hat{\mu}$ that represents all the endogeneities, so that the marginal effects are the estimated subjective social discount rate of ecological investment to improve urban and peri-urban environmental quality as shows in equation (9-10).

$$
\begin{gathered}
\ln y_{u i}=\tilde{\tilde{r}}_{u} \ln \hat{\mu}_{u}+\phi_{u} \ln \tilde{\mu}_{u i}+\varepsilon_{u i} \\
\ln y_{p i}=\tilde{\tilde{r}}_{p} \ln \hat{\mu}_{p}+\phi_{p} \ln \tilde{\mu}_{p i}+\varepsilon_{p i} \\
i=\tilde{\tilde{r}}-\tilde{\hat{r}}
\end{gathered}
$$

where $\tilde{\mu}=\tilde{\mu}_{i}($ gender, age,$e d u$, job, car, saving, current attitude $)$.

Therefore, we can reach the estimated private invest-return rate $i$ calculated by the $\tilde{\hat{r}}$ subtracted from the $\tilde{\tilde{r}}$ shown in the following equation (11), which illustrates that 
the environmental income effects initiate returns on ecological investment with aging effects for future environmental improvement.

\section{Results}

If people unsatisfy their current living status, their time preference can be much lower. In this case, they prefer to consuming present more than saving for future consumption. In empirical model I, we firstly suppose all respondents dissatisfy current environmental infrastructures, and then test the gap between the estimated subjective social discount rate and private discount rate of ecological investment to estimate the uncertain part of private discount rate. Thus, we reach the estimated social discount rates of ecological investment are about $12.8 \%$ for improving urban environmental infrastructure, and 7.24\% for peri-urban environmental infrastructure in Beijing. The estimated time preference rate is about $1 \%$ which is close to our assumption. In empirical model II, we test the endogeneities of income and saving rise to the change of this uncertain part of private discount rate. We estimate this can increase about $1.66 \%$ to reach higher estimated subjective social discount rates about $14.46 \%$ for urban environmental infrastructures improvement, and increase $1.62 \%$ to reach $8.86 \%$ for peri-urban environmental infrastructures improvement. The estimated time preference rate then can increase to about $1.72 \%$. In empirical model III, we further estimated social discount rates of urban and peri-urban ecological investment by employing the predicted private discount rate (prediction of empirical model II), which are about $22 \%$ and $27.3 \%$. Then, we reach the expected rate of return on ecological investment about $7.54 \%$ for urban environmental infrastructures improvement which is much lower than $18.37 \%$ for peri-urban environmental infrastructures improvement. It indicates that ecological investment to peri-urban environmental infrastructures has a higher rate of 
return of ecological investment because of the effects of income rises via individual choices of willingness-to-invest.

Our estimated results show that the effects of income rise can initiate the rise of return on ecological investment to improve peri-urban environmental infrastructures by recalling the distribution of survey respondent expect rate of return on ecological investment in figure 1. Wang \& Deng (2017) have analyzed that the status-seeking effects can drive higher willingness-to-pay for ecological investment. Such as education and beliefs can endogenously shift these income effects. For instance, people are willing to pay less for improving environmental infrastructure if they consider the roads have some close relationships with environmental quality. It basically means environmental amenities are prone to be like luxury goods when good environmental quality become scarce, and that may not follow the diminishing utility rules when people believe their health are closely linked to good environmental quality. Thus, people would like to invest more on environmental infrastructure to improve environmental quality and keeping healthy when their income rise.

Results of Empirical Model I III on survey respondent expected private discount rate of ecological investment to improve environmental infrastructures in urban and peri-urban area in Beijing of China, 2016 is shown in Table 2.

From the results of empirical model I, the marginal coefficient of expected rate of return on ecological investment is 0.066 , the coefficient of income rise is 0.075 , and the sum of coefficients of satisfaction of current consumption and respondent awareness of ecological infrastructure is -0.831 , then simply calculated the estimated social discount rate is $0.066+0.075 * 0.831=12.8 \%$ for urban ecological investment, and $7.24 \%$ for periurban ecological investment in the same way of calculation. Moreover, higher social 
status increase willingness-to-pay for ecological investment. Thus, higher income and saving increase ecological investment. It demonstrates the effects of income rises can initiate future returns on current ecological investment. Estimated respondent time preference for urban ecological investment is $0.066-0.075^{*} 0.831=0.0037$, and -0.0024 is for peri-urban ecological investment, thus, the pooled estimated respondent time preference in Beijing about 1\%o. It is close to our survey assumption that all respondents are somehow unsatisfied current environmental infrastructures.

From the results of empirical model II, we estimate the pooled endogeneities of impact factors to the expected rate of return on ecological investment changes. We find that economic status does not show statistically significant to alter the expected rate of return on ecological investment. While respondent current attitude of food and housing consumption and their social status are significant. It implies that economic status does not have too much influence to the expectation of returns on ecological investment. Instead, their aging effect can initiate the expectation which further illustrates that people would like to pay for improving living environmental conditions for living longer when they are getting older. The coefficient of age to the expected rate of return on ecological investment is about 0.061 , which means there is 6 percent of probability increases to respondent expected rate of return on ecological investment when getting older every one year old from the sample mean at 51 years old. We calculate the endogeneities of impact factors to the expected rate of return on urban ecological investment in next following year about $(1+0.066) * 1.5 \%+0.036 * 0.02=1.66 \%$, which is the estimated coefficient of expected rate of return on urban ecological investment 0.066 in model I plus one and then times by the mean of survey respondent expected rate of return on ecological investment $1.5 \%$ to reach $(1+0.066) * 1.5 \%=0.0159$, and then 
plus the product of the coefficient of income rise 0.036 and the sum of coefficients of satisfaction of current consumption and respondent awareness of ecological infrastructure -0.02; similarly, the endogeneities of impact factors to the expected rate of return on peri-urban ecological investment about $(1+0.035) * 1.5 \%+0.036 * 0.02=1.62 \%$. Thus, we reach the updated estimated subjective social discount rate about $12.8 \%+1.66 \%=14.46 \%$ for urban ecological investment, and $7.24 \%+1.62 \%=8.86 \%$ for per-urban ecological investment. Furthermore, we can reach the updated estimated time preference rate about $1 \%$ o $+0.036 * 0.02=1.72 \%$.

From the results of empirical model III, we estimate the subjective social discount rates with plugging the predictions of uncertain part of the private discount rate from model II which are about $22 \%$ for urban ecological investment, and $27.3 \%$ for periurban ecological investment. Thereby, the private estimated rate of return on ecological investment are about $22 \%-14.46 \%=7.54 \%$ for urban ecological investment, and $27.3 \%$ $8.86 \%=18.37 \%$ for peri-urban ecological investment when income rise and happiness increases by environmental infrastructures improvement to environmental quality improvement.

Table 2 Results of Empirical Model I III on survey respondent expected rate of return on ecological investment to improve environmental infrastructures in urban and periurban area at Beijing of China, 2016.

\section{Discussion}

Empirical results have shown that ecological investment to improve environmental infrastructures based on individual willingness-to-invest can efficiently initiate a profit 
space because of income and happiness increase in the future. Car owners and senior people are highly likely interested into investing environmental infrastructures if they believe some close relationships between their living and environmental quality. Satisfaction of energy and housing conditions are much sensitive to the trade-offs of utilities changes in between present consuming and savings for future consumption.

The 'per capita' statistics is quite significant to energy policy application in urbanizing regions. On the one hand, urban population geometrically increases with non-linear increases of resource utilization. Personal experiences tell us that immigration into cities that is the household behaviors. There are at least one to three family members who will follow a new resident into cities. Moreover, more senior people are seeking to move into cities. There are 0.22 billion senior people over 60 years old, about over 16 percent of total population in current China. Whereas, most hospitals and high-qualified education institutes in China are located in the cities. Once urbanization lets more senior people move into cities, the satisfaction of energy use and housing conditions may suffer from a larger decrease in the future.

Urban population and their prosperous consumption demand for high quality goods and services induce this high level of urban energy consumption. Urban area is less than rural residential area in China, but the urban energy consumption accounts for over five times higher than non-urban area until 2010. Industrial policies on energy saving may have different outcomes at firm level in some regions. Such like power industry reformation policy in China is highly debatable. The fix price generates low economic efficiency of electricity consumption in urban area, and long distance of electric power transmission cause some power loss. It leads to urban electricity supported by relatively close regional power factories even if China has advanced system of electric power 
transmission. Energy structural reformation in north China is still very hard because regional power supply depends upon coal thermal power stations. Consequently, cleaner energy supply to north China confront a higher transaction cost. Engineeringbased energy saving innovation also confronts relatively higher cost of interconnection to power system, such like feed-in tariffs (FIT) policy may depend upon more regional policy and across regional price mechanisms. Whereas, this scheme has quite weak linkage to urban energy demand.

Furthermore, we are experiencing the reallocation of urban population in a social transformation. After President Xi inspected Beijing municipal government about urban development on Feb 26 ${ }^{\text {th }}$, 2014, Beijing-Tianjin-Hebei coordinative development has stressed the project of 'Beijing population dispersal engineering' ('北京市人口疏 解工程' in Chinese). There were more than 500 thousand non-local resident population who have left Beijing during recent three years. Some other huge cities like Shanghai, Guangzhou, Shenzhen also take this kind of plan to control the increase of urban population. Such as US in 1940s, over 120 million people were encouraged to move to suburban area. China may also experience this kind of developing stage. We have observed that urban energy consumption is decreasing in recent five years. However, it is different from US that Chinese people who live in peri-urban area actively commute to urban area frequently. This intensifies transportation energy consumption. If there are no attractive policies that can orient people move to suburban area, most of them may still choose to live close to urban as much as they can close to healthy centers and high-qualified education institutes.

Opening the landscape rights to individual willingness-to-invest for improving environmental quality is a good option. The concept of crowdfunding operation can 
benefit to improve resource reallocation for urban-rural co-development. On the one hand, senior people are looking for higher quality of environment to their ideally longer living. Short-term-tourism in suburban, rural regions, and those regions close to natural conservation parks have absorbed a part of retired people. Whereas, senior people cannot stay a long period of time in there because there are much less high-qualified hospitals and education institutions. For example, Mr. Wang, a middle-class Beijing resident, got heart attack due to cardiovascular burst at their villa in Sanya of Hainan Province. Because he did not have health insurance at Sanya, and where even no highqualified hospital could secure him, they had to pay for 500 thousand CNY right away to rent a flight back to Beijing. Fortunately, he has been saved and recovered. Our survey number shows over 60 percent of respondents who want to own two houses in rural and urban regions, but over 50 percent of respondents who would not afford that. Moreover, there are much less people like Mr. Wang who can pay for an emergence flight. On the other hand, current policy encourages senior people relying on current community resources may induce more urban problems, such like much crowding in the hospitals during rush-hours, and that aggravates transportation demands of senior people whom may face to a higher healthy risk in crowds.

Pay a part of pensions to hold temporal permits to living in senior villages close to the places with advanced environmental amenities. The empirical model III results that to initiate energy policy and housing satisfaction can decrease the payment share to improve environmental infrastructures about $20 \%$ in urban area, and $10 \%$ in peri-urban area. It can be explained by the Jevons' paradox that the more energy we current consume, the more energy we need for future consumption. This is the critical reason that low community acceptance to using renewable energy in developed countries 
because the price rise can be doubled. There are $72.7 \%$ of respondents in this survey who stated that they do not want to permanently move to other places mainly because their living habits, and they consider to move only if for a temporal recreation, so that near to $60 \%$ of respondents want to own two or more houses in both urban and rural area, but only less than $5 \%$ respondents aim to get returns on investment to real estate. Therefore, policy outlets or central planning program to develop this kind of huge aging market with tourism development may be some good options.

\section{Policy implications}

More private investment and crowdfunding projects should be embraced to stimulate individual behaviors for public common will of environmental conservation. Because the efficiency of government investment for environmental governance is quite arguable in public opinions. For instance, reported by P.R. of China National Bureau of Statistics, ecological investment for forestry in Beijing accounts for 1.8 percent of the national total investment for environmental governance in 2015. Beijing municipal government announced to invest 760 billion CNY for environmental governance to reduce the haze. However, air pollution is still severe in Beijing. Thus, government investment to environmental governance is very debatable in urban laws, urban-rural planning, and political schemes in some regions.

Public opinions can be much influenced by local cultural factors. In the history of England and some other European countries, decentralization challenges the parliamentary system which let central policies become very hard to be accepted and implemented at community level mainly because of regional resource endowment. Thereby, liberals incline to self-manage via free trade to promote higher income rise and limit endowment effects to make high-profit from monopoly and oligopoly 
production. In energy use, the feed-in tariffs policy is a kind of harmonious price strategy for adjacent regions to bargain the price of electricity. However, local myopic people much care about recent living cost and environmental changes rather than future grand-generations' benefits. This somehow lets other far sight local people lose the chance to invest green energy business. Particularly, in the information era, there are prosperous demands to join social groups and develop new-type of experiential business to help and make profit from far-sight investment to non-local regions environmental conservation. This differs from charity even if the invested place can be in physical distance far from daily living; and it differs from financial derivatives in virtual economy even if people can make profit from price rise of their subscribed rights. The Coase theorem has proved the clarification of property benefit to improve economic efficiency. More importantly, Elinor Ostrom has provided evidence about selfish profit maximization can be compromised to a higher level of common profits from public choices. This is the core-concept of crowdfunding currently. Therefore, this paper provides some evidence of this core-concept that can be used to study the return on ecological investment for better saving energy and to make environment greener.

\section{Conclusions}

In this research, we estimate social discount rate of ecological investment for improving environmental infrastructures (including ecological infrastructures and public gray infrastructures) by using the survey data of private expected invest-return rate and its impact factors (including personal identity, social status, economic status, satisfaction of current consumption, and awareness of ecological infrastructures). Empirical model I III report that there are some profit spaces for crowdfunding operation of private ecological investment aiming to improve environmental quality and develop the aging 
market. The estimated private invest-return rate can reach to $7.54 \%$ for urban and $18.37 \%$ for peri-urban ecological investment.

Ecological investment to peri-urban environmental infrastructures has a higher invest-return rate because of the effects of income rises via individual choices of willingness-to-invest. The empirical model I reports that the estimated social discount rates of ecological investment are about $12.8 \%$ for improving urban environmental infrastructure, and $7.24 \%$ for peri-urban environmental infrastructure in Beijing. The estimated time preference rate is about $1 \%$ which is close to our assumption that all respondents dissatisfied current environmental infrastructures. In empirical model II, we test the endogeneities of income and saving rise to the change of this uncertain part of private discount rate, which can increase about $1.66 \%$ to reach a higher estimated subjective social discount rate about $14.46 \%$ for urban, and increase about $1.62 \%$ to reach $8.86 \%$ for peri-urban environmental infrastructures improvement. The estimated time preference rate can increase to about $1.72 \%$. In empirical model III, we further estimated subjective social discount rates of urban and peri-urban ecological investment by employing the predicted private discount rate (predictions of empirical model II), which are about $22 \%$ and $27.3 \%$. Then, we reach the invest-return rates about $7.54 \%$ for urban environmental infrastructures improvement which is much lower than $18.37 \%$ for ecological investment to peri-urban area.

Policy implication about satisfactions of energy use and housing are much sensitive to social discount rate changes, which can increase the dissatisfaction of residential happiness because of an increasing price mechanism when 'per capita' resource faces to decline. Therefore, we suggest opening the landscape rights to individual willingness-to-invest for improving environmental quality, and providing options to let 
people pay a part of their pensions for temporal permits to living in some well-served villages close to the places with advanced environmental amenities which are supported by central planning policy via the crowdfunding projects. This is the core-concept that the collaborative investment to an integrated management scheme makes profits for public common amenities. It means to share blurry rights of public properties but manage them in an individual's manner for earning profits together under an integrated scientific monitoring framework.

\section{Acknowledgement}

This study was financially supported by research projects of the International (regional) Cooperation and Exchange Programs by the National natural science foundation of P.R. of China (Grant no. 71561137002), the Key Project of National Natural Science Foundation of P.R. of China (Grant No. 7153000125), and the National Key Research and Development Program of P.R. of China (Grant No. 2016YFA0602500); and the Joint-PhD program funded by China Scholarship Council (Grant No. 201606510044).

\section{Conflicts of Interest}

The authors declare no conflict of interests.

\section{Reference}

Ang, B. W., Su, B., \& Wang, H. (2016). A spatial-temporal decomposition approach to performance assessment in energy and emissions. Energy Economics, 60, 112121.

Baumol, W. J. (1968). On the social rate of discount. The American Economic Review, $58(4), 788$.

Bauwens, T. (2016). Explaining the diversity of motivations behind community renewable energy. Energy Policy, 93, 278-290.

Cao, X., Kleit, A., \& Liu, C. (2016). Why invest in wind energy? Career incentives and Chinese renewable energy politics. Energy Policy, 99, 120-131.

Chen, Z. M., Chen, G. Q., \& Chen, B. (2013). Embodied carbon dioxide emission by the globalized economy: a systems ecological input-output simulation. Journal of Environmental Informatics, 21(1), 35-44.

Dasgupta, P. (2008). Discounting climate change. Journal of risk and uncertainty, 37(2-3), 141-169.

Deng, X., Huang, J., Uchida, E., Rozelle, S., \& Gibson, J. (2011). Pressure cookers or pressure valves: do roads lead to deforestation in China?. Journal of Environmental Economics and Management, 61(1), 79-94. 
Forman, R. T., \& Wu, J. (2016). Where to put the next billion people. Nature, 537, 608611 (29 September 2016). doi:10.1038/537608a

Harrison, M. (2010). Valuing the Future: the social discount rate in cost-benefit analysis. Available at SSRN 1599963.

Hess, S. (2010). Nail-houses, land rights, and frames of injustice on China's protest landscape. Asian Survey, 50(5), 908-926.

Huang, C., Su, J., Zhao, X., Sui, J., Ru, P., Zhang, H., \& Wang, X. (2012). Government funded renewable energy innovation in China. Energy Policy,51, 121-127.

Janssen-Jansen, L. B. (2008). Space for Space, a transferable development rights initiative for changing the Dutch landscape. Landscape and Urban Planning, 87(3), 192-200.

Lee, C. Y., \& Heo, H. (2016). Estimating willingness to pay for renewable energy in South Korea using the contingent valuation method. Energy Policy, 94, 150-156.

Leete, S., Xu, J., \& Wheeler, D. (2013). Investment barriers and incentives for marine renewable energy in the UK: An analysis of investor preferences. Energy policy, 60, 866-875.

Li, F., Liu, X., Zhang, X., Zhao, D., Liu, H., Zhou, C., \& Wang, R. (2016). Urban ecological infrastructure: An integrated network for ecosystem services and sustainable urban systems. Journal of Cleaner Production. doi:10.1016/j.jclepro.2016.02.079

Moriarty, P., \& Honnery, D. (2016). Can renewable energy power the future? Energy Policy,93, 3-7. doi:10.1016/j.enpol.2016.02.051

O'neill, J., \& Walsh, M. (2000). Landscape conflicts: preferences, identities and rights. Landscape ecology, 15(3), 281-289.

Penker, M. (2009). Landscape governance for or by the local population? A property rights analysis in Austria. Land Use Policy, 26(4), 947-953.

Ramsey, F. P. (1928). A mathematical theory of saving. The economic journal, 38(152), 543-559.

Wang, Z., \& Deng, X. (2017). Status-seeking effects on willingness to pay for environmental infrastructure improvement in eco-urbanization, Journal of Environmental Economics and Management, JEEM_2017_83_Original_V1 submitted. working paper at doi: 10.13140/RG.2.2.10595.14885

Wang, Z., Chen, J., Zheng, W., \& Deng, X. (2017). Dynamics of land Use Efficiency in Rapidly Urbanized Beijing-Tianjin-Hebei Region, China, Landscape and Urban Planning, under review. doi: 10.13140/RG.2.1.3969.8165

Wang, Z., Deng, X., et al. (2016). Beijing-Tianjin-Hebei ecological infrastructure and public service survey, Institute of Geographic Sciences and Natural Resources Research, Center for Chinese Agricultural Policy of Chinese Academy of Sciences (CAS), unpublished dataset.

Wang, Z., Deng, X., Liu, G., \& Li, L. (2017). Earning Environmental Income from a Large Open Economy, AER-2016-2009. working paper at doi: 10.13140/RG.2.2.36180.40329

Wang, Z., Deng, X., Wang, P., \& Chen, J. (2016). Ecological intercorrelation in urbanrural development: an eco-city of China. Journal of Cleaner Production. in press. http://dx.doi.org/10.1016/j.jclepro.2016.02.120

Weitzman, M. L. (1994). On the "environmental" discount rate. Journal of Environmental Economics and Management, 26(2), 200-209. 
Zhang, S., Jiao, Y., \& Chen, W. (2017). Demand-side management (DSM) in the context of China's on-going power sector reform. Energy Policy, 100, 1-8.

Zhang, Y. J., Peng, Y. L., Ma, C. Q., \& Shen, B. (2017). Can environmental innovation facilitate carbon emissions reduction? Evidence from China. Energy Policy, 100, $18-28$.

Zhang, Z. (2015). Crossing the river by feeling the stones: the case of carbon trading in China. Environmental Economics and Policy Studies, 17(2), 263-297.

Zhou, P., \& Wang, M. (2016). Carbon dioxide emissions allocation: A review. Ecological Economics, 125, 47-59.

Zhou, P., Sun, Z. R., \& Zhou, D. Q. (2014). Optimal path for controlling CO 2 emissions in China: a perspective of efficiency analysis. Energy Economics,45, 99-110.

Zhuang, J., Liang, Z., Lin, T., \& De Guzman, F. (2007). Theory and practice in the choice of social discount rate for cost-benefit analysis: a survey. ERD Working Paper Series No.94. 